\title{
Involvement of Stakeholders in School Based Self-Evaluation in Assuring Quality Management
}

\author{
Sunshine Namasiku Siafwa*, Peter C. Manchishi, Professor Austin Mumba Cheyeka \\ School of Education, University of Zambia, Zambia
}

*Corresponding Author: Sunshine Namasiku Siafwa, School of Education, University of Zambia, Zambia

\begin{abstract}
Purpose: This paper discusses the involvement of stakeholders in schools during school based self-evaluation (SBSE) for assuring quality management in twenty selected public secondary schools in Lusaka Province, Zambia. It attempts to determine which stakeholders are involved in SBSE in schools in order to assure quality management.
\end{abstract}

Methodology: The research design was a survey and a mixed methods approach was used. Data were collected using interviews and questionnaires. Interviews were thematically analysed and questionnaires were analysed using statistical package of social sciences. The population sample of 360 was used and this included administrators, teachers, pupils and support staff.

Findings: The findings of the study revealed that the administrators and teachers were the most involved stakeholders in a school, while the pupils and support staff were not fully involved. The findings further revealed that the extent of involving the pupils and support staff was not significant enough to attain assured quality management.

Conclusion and Recommendations: On identifying who was involved, the study noted that while all stakeholders understood their roles, the support staff did not understand their role in school management well. This meant that not all stakeholders were involved. The gap in the implementation of SBSE was that one section of stakeholders were left out, which had an effect on assured quality management outcome. The study concluded that without the inclusion of the all stakeholders, SBSE implementation was not complete and therefore, achieving quality management was not assured.

Keywords: School based self-evaluation, Management, Stakeholders, Quality Management, Self-evaluation

\section{INTRODUCTION}

The paper discusses the involvement of stakeholders in schools during school based self-evaluation in assuring quality management in twenty (20) selected public secondary schools in Lusaka Province, Zambia. The study was guided by Deming's Total Quality Management theory. According to Deming's Total Quality Management theory, the framework for transforming schools was based on his 14 TQM principles. Bonstingl (2001) outlined Deming's TQM principles he believed were most salient to education reform. He called them the "Four Pillars of Total Quality Management." These were synergies of relationships, continuous improvement and self-evaluation, system on-going process and leadership. According to Bonstingl (2001) in his first pillar, an organization was to focus, first and foremost, on its suppliers and customers. In a TQM organization, everyone was both a customer and supplier; this confusing concept emphasized "the systematic nature of the work in which all were involved". Kelchner (2008) concurred with Bonstingl (2001) by defining Total Quality Management as a system of continuous improvement that involved all workers in a business from upper management to production line workers. In other words, teamwork and collaboration were essential. Murray (2014) agreed to the definition by Kelchner (2008) by stating that 'TQM took into account all quality measures taken at all levels and involving all company employees. Based on the above pillars, SBSE can be achieved with the involvement of all stakeholders which includes administrators, teacher, pupils and support staff in a school. The study endeavoured to determine which stakeholders were involved in implementing SBSE in their schools. 


\subsection{Background}

The system of evaluation in schools worldwide is going through changes in approach and one of the most innovative change, was moving from schools being evaluated by external evaluators to schools evaluating themselves. MacBeath (2003) stated that the need for schools to evaluate themselves was due to many reasons, in particular the high cost of external inspection systems and further stated that the direction of school and teacher evaluation in many education systems was undoubtedly moving towards internal school based self-evaluation. Grauwe and Naidoo (2004) suggested that selfevaluation was at the centre of almost all education quality improvement policies and strategies in most countries today.

Therefore, self-evaluation has the merit of being immediate, responsive to the school's specific needs and circumstances and its results are 'owned' by the school (OCED, 2009). When evaluation is conducted from within the school it is referred to as school based self-evaluation.According to MacBeath (2005a) self-evaluation is a process of reflection on practice, made systematic and transparent, with the aim of improving pupil, professional and learning outcomes.

Zambia has joined the rest of the world in introducing school based self-evaluation in schools. Furthermore, Zambia has been part of many world conferences that have discussed ways of improving the quality of education as part of the agenda. According to the policy document, 'Educating our Future' quality in education would be better assured if schools were dynamic in their pursuit of excellence (MOE, 1996: p.159). The document 'Educating our Future' is the national policy, therefore SBSE is a policy for public schools in Zambia.

In an effort to ensure that quality delivery of education took place, the Ministry of General Education revised the Standards and Evaluation guidelines of 1997 in 2015. In these guidelines highlights governing the implementation of self-evaluation by schools are given. The revision was important as it now called for all stakeholders to be involved in evaluating their contribution in their schools, which signified that the schools were now engaged in helping the system to achieve quality education.

\subsection{Review of Related literature}

The concept of self-evaluation was diverse because it depended on the dimension one was looking at. In a school setting a number of evaluations can be done, some of which are teacher evaluation, student evaluation, school evaluation and system evaluation. In this study evaluation took the form of school based self-evaluation. Scheerens (2002) defined the term school based self-evaluation as 'the type of evaluation where the professionals in the programme or core service of the organisation carry out the evaluation in their own organisation. The process of carrying out the core service of the organisation involves stakeholders to ensure that success was achieved. To achieve this, it was important that the stakeholders were all fully involved in the process. The study endeavoured to determine which stakeholders were involved in SBSE in schools.

The process of effective school based self-evaluation would bring about enhanced positive attitude/approach by all stakeholders, by so doing management would concentrate on more pertinent issues and would be able to make meaningful follow ups and this would bring about assured quality management School self-evaluation effectively implemented would bring about teamwork. Teamwork would be enhanced due to collaboration involving all stakeholders who would contribute to the process of school based self-evaluation at their levels. Collaboration means everyone being aware of their role in improvement of the school in their section as well as being aware of what was going on in the rest of the school. Checutti (2005) posited that a culture that promoted quality was painstakingly created by those schools; where the staff was fully committed and felt deeply responsible for the achievement of the vision; where a climate of collaboration and participation by all stakeholders permeated all initiatives, each and every one was determined to become an agent of change. Engaging staff members, volunteers, and other stakeholders in the design and implementation of an evaluation would provide opportunities for skill building and learning (NOAA, 2000).

Open, honest and robust self-evaluation requires good communication among all those with a stake in the school: the staff, governors, pupils, parents and the school's partners. All members of the school community need to recognise their contribution to the schools' success and the actions required for further improvement (Ofsted, 2006). Effective school self-evaluation provided the school with a mechanism to engage in open and transparent communication with the entire school community (DES, 2012). 


\section{MeTHOdOLOGY}

The design of the study was a survey and a mixed approach which was used concurrently. Quantitative and qualitative methods were used to collect data. Data were collected during the first and second term (February- July) -2016 school calendar year.

A sample population of 360 participants selected from twenty public schools was used. In this study, non- probability sampling procedure was used, specifically purposive sampling to select the 20 public secondary schools. Two schools from each of the 7 districts in Lusaka were sampled and 6 schools from Lusaka district due to the fact that it has a lot of schools. Total of 360 participants which included 80 administrators, 4 per school; 120 pupils, 6 per school; 120 teachers, 6 per school and 40 support staff, 2 per school were sampled. There were 61 male teachers and 59 female teachers interviewed. The criterion for picking the sample population was that the teachers would have been in that particular school for a minimum of one year.

The researcher used semi-structured interview guides and questionnaires. The researcher gave out self-administered questionnaires to teachers which were collected after each participant completed answering. This ensured that all questionnaires were collected. After answering the questionnaires, the same participants were engaged in a focus group discussion which lasted for about 40-50minutes. With permission from the participants, the researcher recorded the discussions using an audio recorder to ensure accuracy of interview data. Face to face, in-depth interviews involving administrators were held. Qualitative method was used in order to develop in-depth understanding if the stakeholders in schools were involved in the implementation of SBSE to assure quality management, which was thematically analysed. For quantitative method the statistical package for social sciences (SPSS) was employed to translate findings into frequency tables and graphs to further collaborate the findings with the interviews that had been conducted.

\subsection{Scope of the Study}

This study focussed on determining which stakeholders were involved in implementing school based self-evaluation in assuring quality management in 20 selected public secondary schools in Lusaka Province, Zambia.

\section{FINDINGS AND DISCUSSION}

The objective of the study was todetermine who was involved in school based self-evaluation in assuring quality management

\subsection{Interviews with Administrators}

The findings from the responses of most of the administrators indicated that teachers were involved in the planning of teaching and learning as well as in decision making. This was during staff meetings and at departmental level where teaching activities were planned. The review of effectiveness of teaching was done in departments regularly. The findings revealed that the resolutions on planning and decision-making in departmental meetings were later relayed to management during management meetings by HODs.

One Head teacher indicated that:

We involve teachers of course in a number of ways, through staff meeting, in their departments they plan as a group and during their CPD planning session.

The findings revealed that involvement of teachers was during CPDs, evaluating their performance in teaching, selecting various teaching methods, demonstrations on how to teach difficulty topics and teachers were also involved in finding solutions which were pertaining to teaching and learning. It was revealed that the departments had powers to swap teachers to teach topics or grades they were comfortable to teach. All the resolutions of these meetings were delivered to the administration through the Heads of Department.

One HOD had this to say:

Yes we involve all teachers through us the HODs, as we meet in our departments and discuss issues pertaining to their performance. The resolutions are then brought to the Deputy who takes them to the Head. 
When asked on whether teachers were involved in decisions to do with the curriculum, the study revealed that the teachers were only involved in deciding how to teach the curriculum effectively. The actual curriculum was designed by the Ministry of General Education and sent to schools for implementation. The teachers through the departments could only discuss the approach to effective application of the curriculum, no drastic changes could be made by the schools, especially on the new curriculum which had compulsory pathways. One Head teacher responded that:

Decisions on the curriculum are far-fetched because they are issues of policy. One time we made a decision to include Biology to a class that had a curriculum pattern that did not include Biology. After discussing with the teachers we implemented, when we informed the Ministry about the decision and we were told to reverse. After reversing we were again told to include Biology.

Asked on who coordinated evaluation, the study revealed that, the CPD coordinator, and deputy Head were named. The findings revealed that there was inconsistency in the response as to who coordinated the activities of school based self-evaluation in most of the schools. In some of the schools even the head teachers were not sure, as to who coordinated it.

Although all administrators indicated that the teachers were involved in planning, decision making and actual monitoring, teaching and learning, there was no mention of pupil involvement. Deming (2000) asserts that the primary task of leadership was to narrow the amount of variation within the system, bringing everyone toward the goal of perfection. Engaging staff members, volunteers, and other stakeholders in the design and implementation of an evaluation would provide opportunities for skill building and learning (NOAA, 2000). Nevo (2002) emphasised on school and teacher autonomy and on self-regulation and internal evaluation as the best way forward.

It is worth noting that the involvement of teachers was through staff meetings, departmental meeting, CPDs and staff briefing. Rudd and Davies, (2000) in their findings agreed that the implementation of school self-evaluation helped the LEA to develop an overview of how their schools are performing. School self-evaluation in this respect, has a professional development function. In this study a platform for teachers to help improve standards of the school was available through the meetings which evidently had minutes.

This in conformity to MOESVTEE (2015) which states that:

For effective planning the school should use a strategic plan, an annual work plan and budget with a clear schedule of activities.

Key activities include:

- Head of department and staff meeting

- General meeting with all teaching staff and management

- Subject association/Continuing Professional Development

- Internal monitoring/supervision

- Head Teachers' meetings with deputy heads, heads of department and senior teachers.

Interviews with Teachers

Questionnaires with Teachers

\section{TEACHERS}

Table 1 below shows 56.9 percent of the teachers interviewed stated that they were involved in evaluations while 43.1 percent claimed they were not. More than 50 percent of the teachers affirmed to being involved in evaluations.

Table1: Involvement of teachers in evaluation

\begin{tabular}{|l|l|l|}
\hline \multicolumn{2}{|c|}{ Are you involved in evaluating any area? } \\
\hline & \multicolumn{1}{|c|}{ Frequency } & \multicolumn{1}{c|}{ Percentage } \\
\hline Yes & 70 & 56.9 \\
\hline No & 30 & 43.1 \\
\hline Total & 100 & 100.0 \\
\hline
\end{tabular}


The findings revealed that of those teachers that said were involved in evaluation of some areas in the school, 62 percent said it was through evaluation of pupils' academic progress through tests, and exams as well as pupils personal well-being. Others stated that they evaluated teachers' performance 23 percent while others said were involved in self-evaluation 12 percent. Figure 1 below shows that all teachers were involved in one way or another. The figure 1 shows results contrary to table 1 where 43.1percent of the teachers said they were not involved. The figure 1 below shows that all of the teachers were involved in evaluation of one area or another.

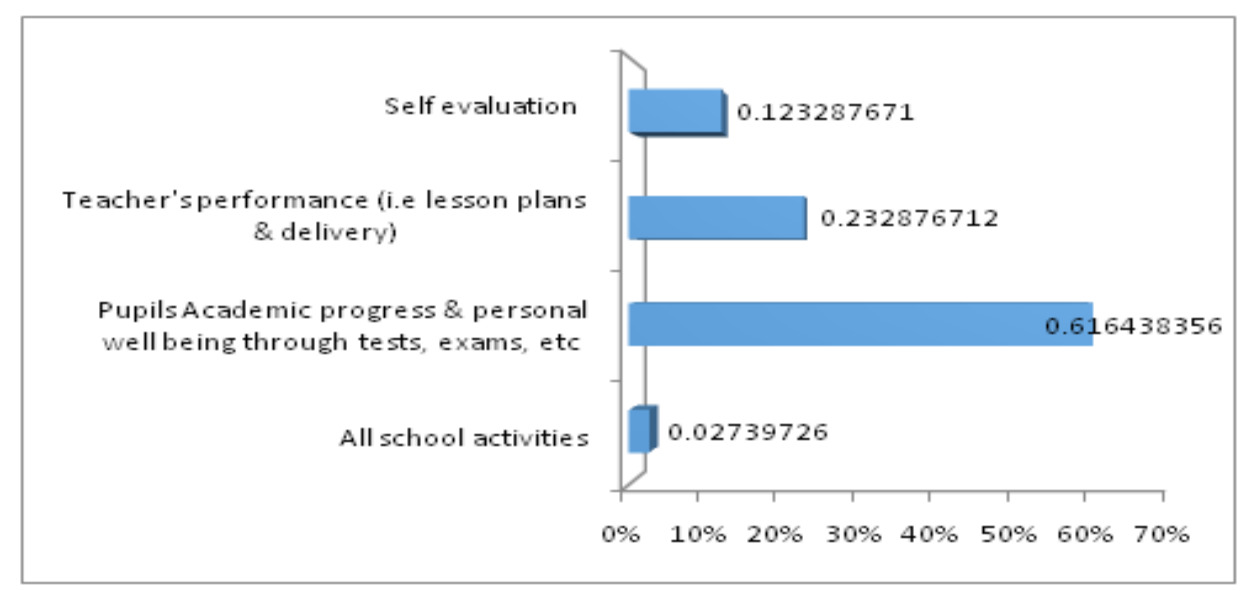

Figure1: Areas that are evaluated

Figure 2 below shows teachers who said that they were involved in evaluating their work as ninety 93 percent and those who did not were 7 percent. This figure shows that almost all of them were involved.

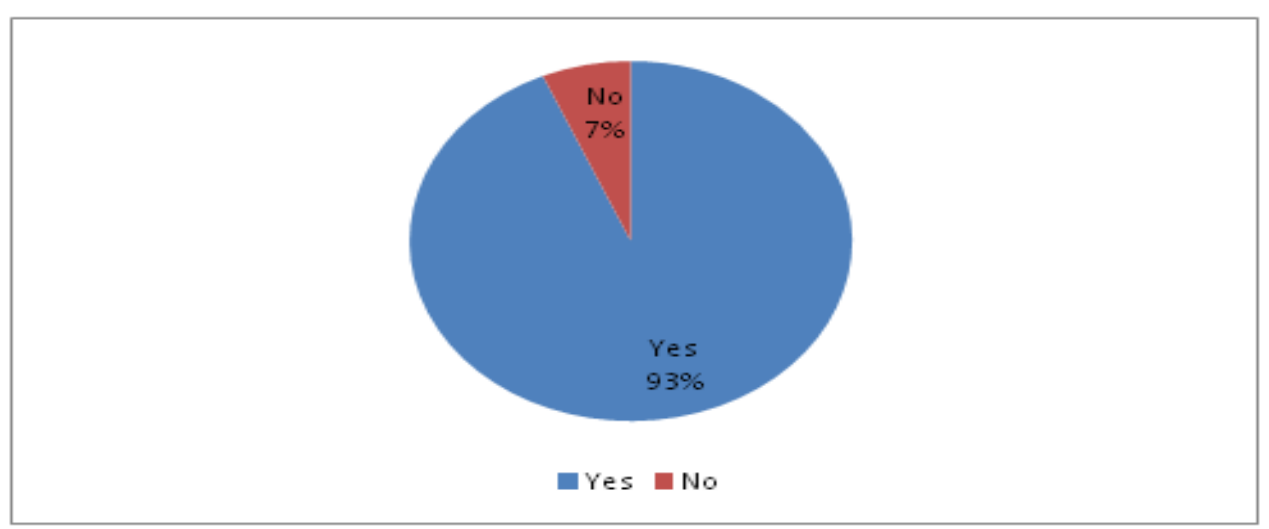

Figure2: Teachers evaluating teaching and learning

Figure 3 shows responses by teachers who said that pupils were involved in accounting for their performance as 78 percent and those who said they did not was 22 percent. Most of the teachers indicated that the pupils were involved.

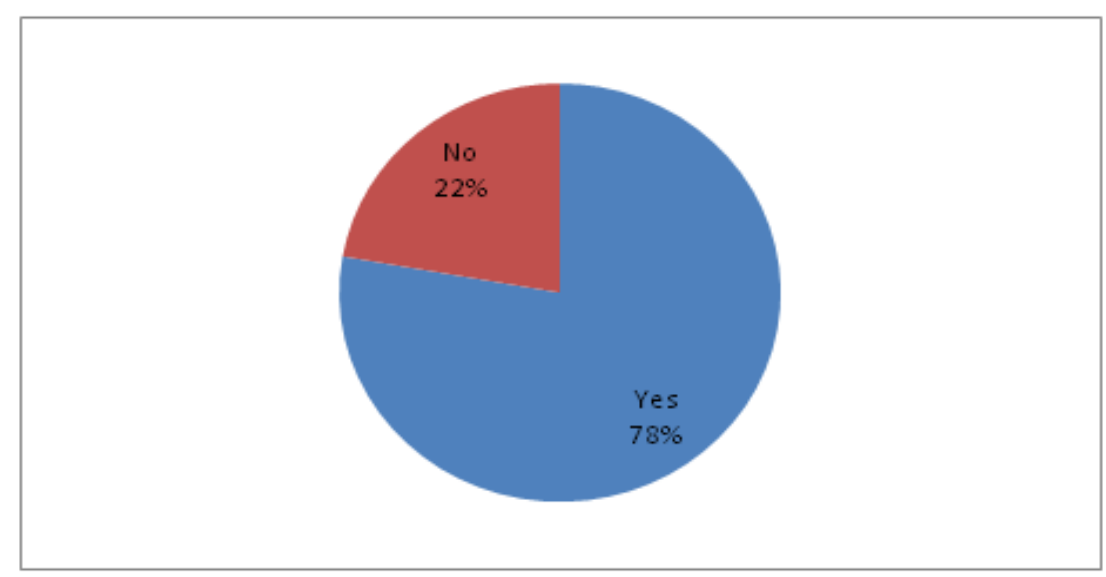

Figure3: Pupils involved in accounting for their performance 
Figure 4 shows the frequency and percentage rate of the teachers that responded on the involvement of everyone in school based self-evaluation in their school. Frequency shows 87 which translated to 77.7 percent agreed that the policy involved everyone and the frequency of 25 which translated to 22.3 percent did not agree the policy in their schools made everyone account for their work. Only a few of the teachers responded that the policy did not make them account for their work.

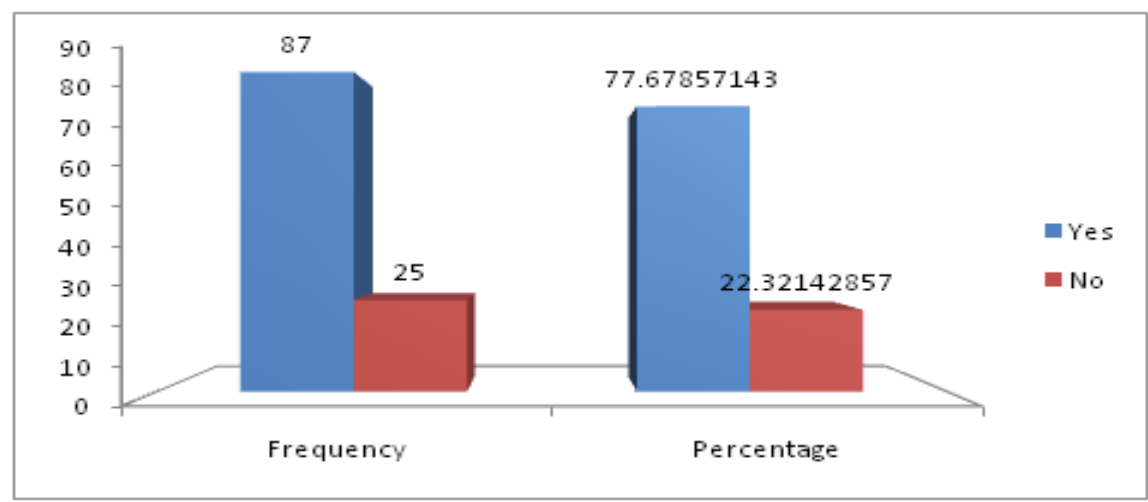

Figure4: Policy to make everyone account for their work

Figure 5 shows the percentage of teachers' responses on how pupils accounted for their performance. Those who said analysing and accounting for individual performance were 9 percent, participating in open day activities were 10 percent, receiving awards/punishments depending on performance 13 percent, participating in classroom activities such as class exercises on revisions 20 percent and through constant assessment such as tests and quizzes 47 percent. All of the teachers stated that the pupils accounted for their work in one way or the other.

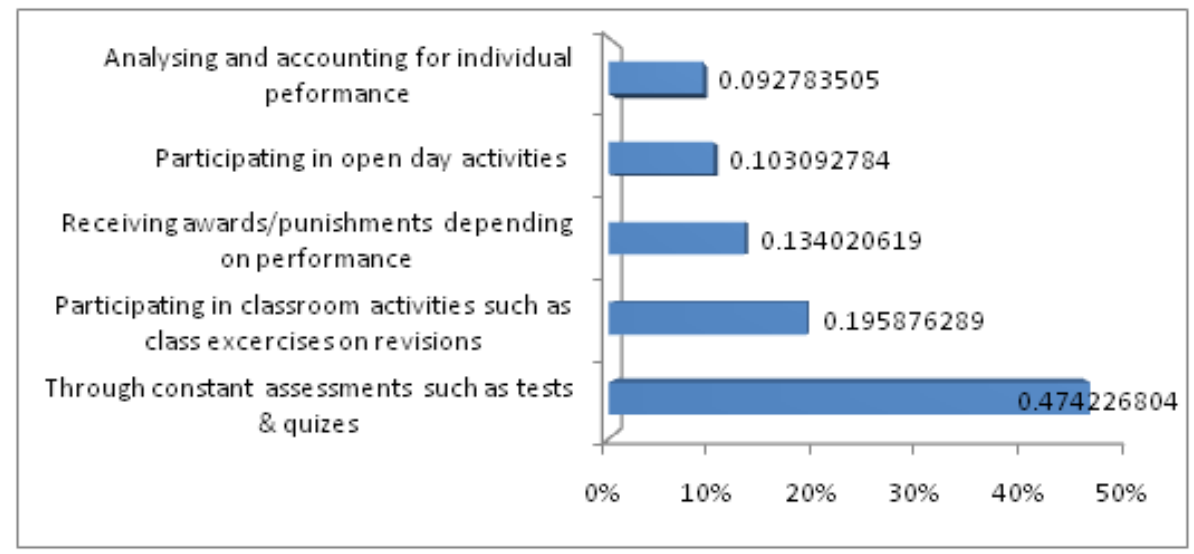

Figure5: Involvement of Pupils-accounting for their performance

Figure 6 below accounts for responses by the teachers to show if everyone was involved in school based self-evaluation. 66.4 percent said yes and 33.6 percent said no. The findings revealed that more teachers said everyone was involved.

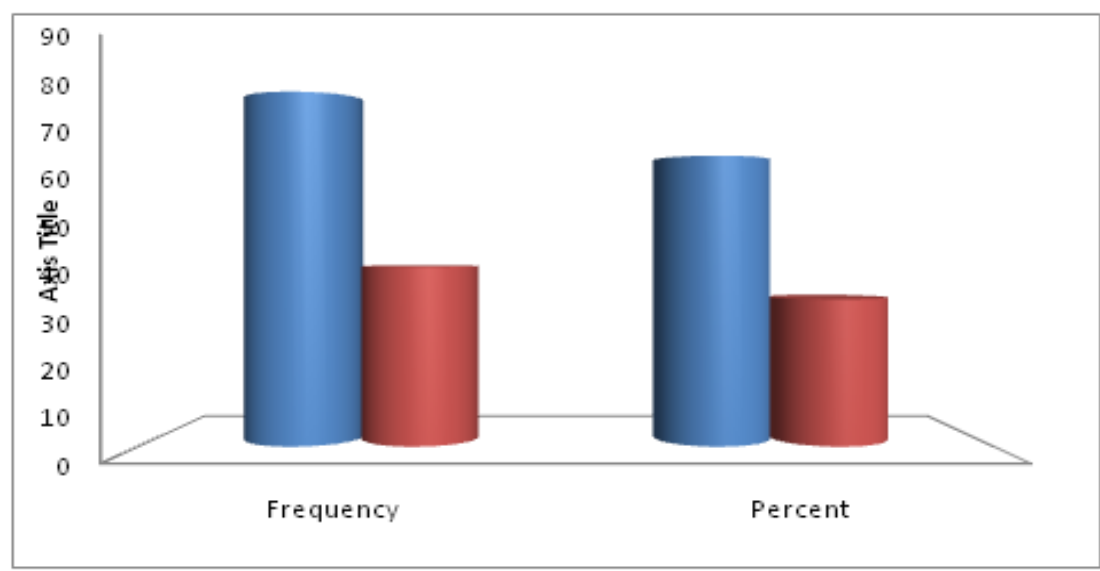

Figure6: Involvement of everyone in school based self-evaluation 
Figure 7 below shows responses on how everyone was involved and most of the teachers' responses focused on monitoring of pupils understanding of lessons delivered, pupils' performance in tests and exams as well as monitoring of the lesson preparations, presentation and delivery by the school administration. 12 percent said teachers were involved through CPDs. 32 percent pupil assessment and 56 percent through lesson plan. The figure 7 below indicates that contrary to figure 8 where some teachers said that that everyone was not involved, Figure 7 shows that everyone was involved in one way or the other.

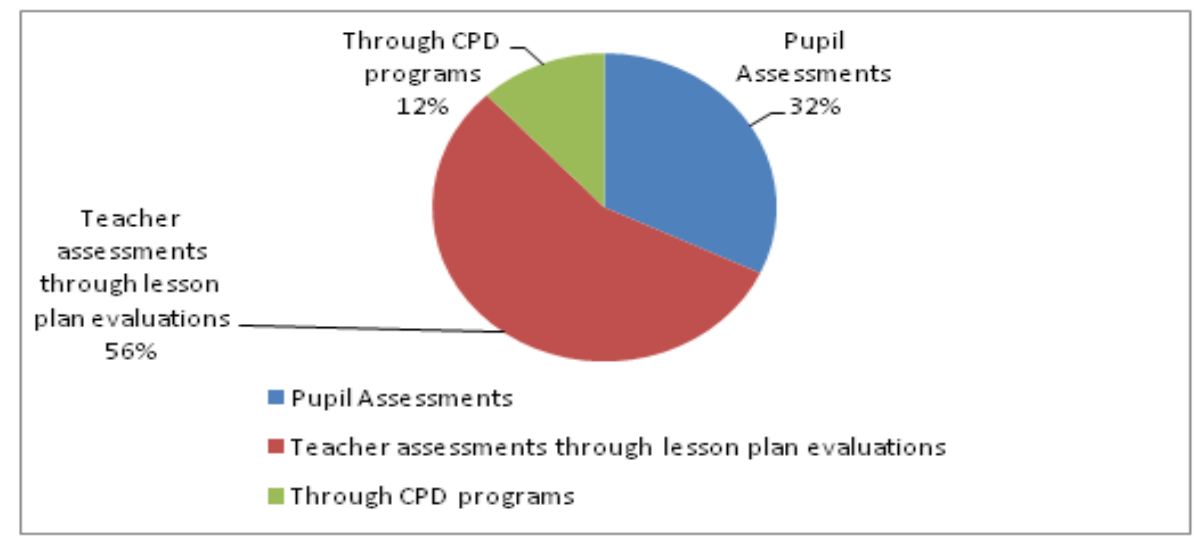

Figure7: How everyone was involved in evaluation

Source: Researchers' Field Work

Of the sampled teachers, 59.2 percent of them responded that were involved in decision making while 40.8 percent said they had no decision making powers in their schools. The figure 8 below shows that more than half the teachers said they were involved in decision making.

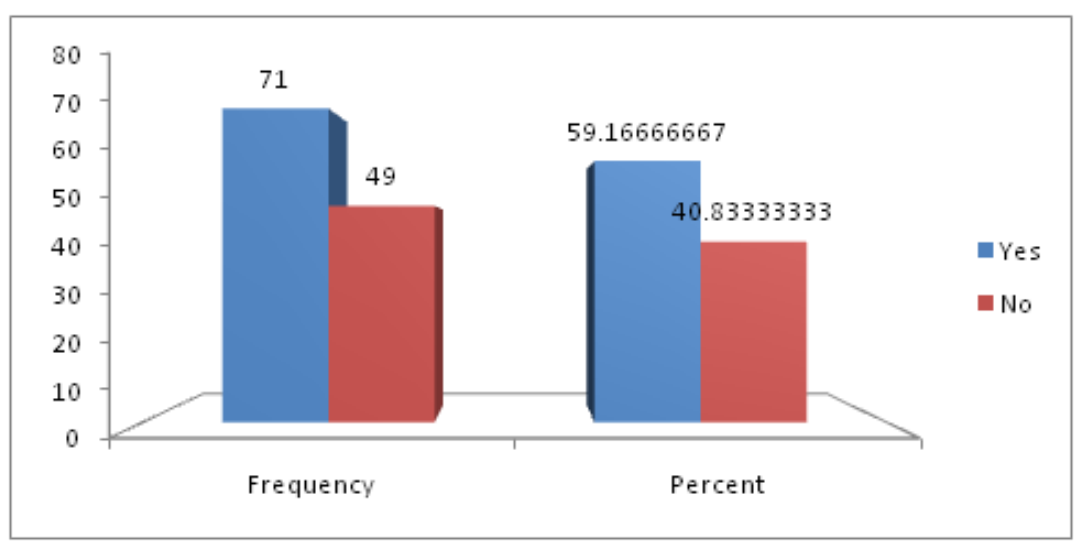

Figure8: Participant's involvement in decision making

Of the sampled teachers, only 22 percent stated that were involved in the formulation of school curriculum while the majority, 78 percent, said they were not involved. Figure 9 below shows this information.

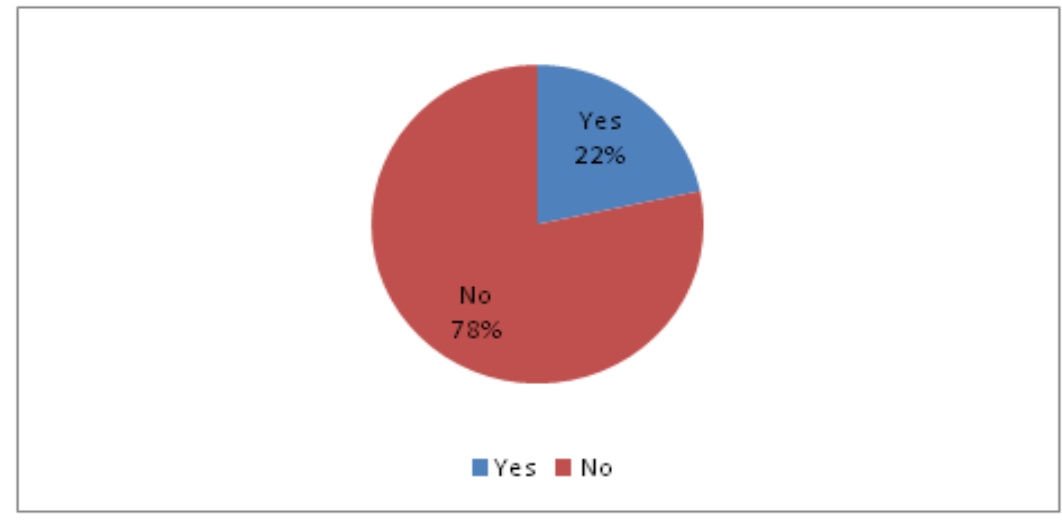

Figure9: Involvement in curriculum formulation 
The findings revealed that when the teachers were asked who coordinated the school evaluations, 14percent said it was the CPD coordinators and 16 percent indicated that it was the Deputy Head and HODs, 38 percent of the teachers said it was the deputy head or the head of their departments while 31 percent claimed it was the school administration (HODs, Deputy Head \& the Head teacher). The figure 10 tabulates the distribution of these findings.

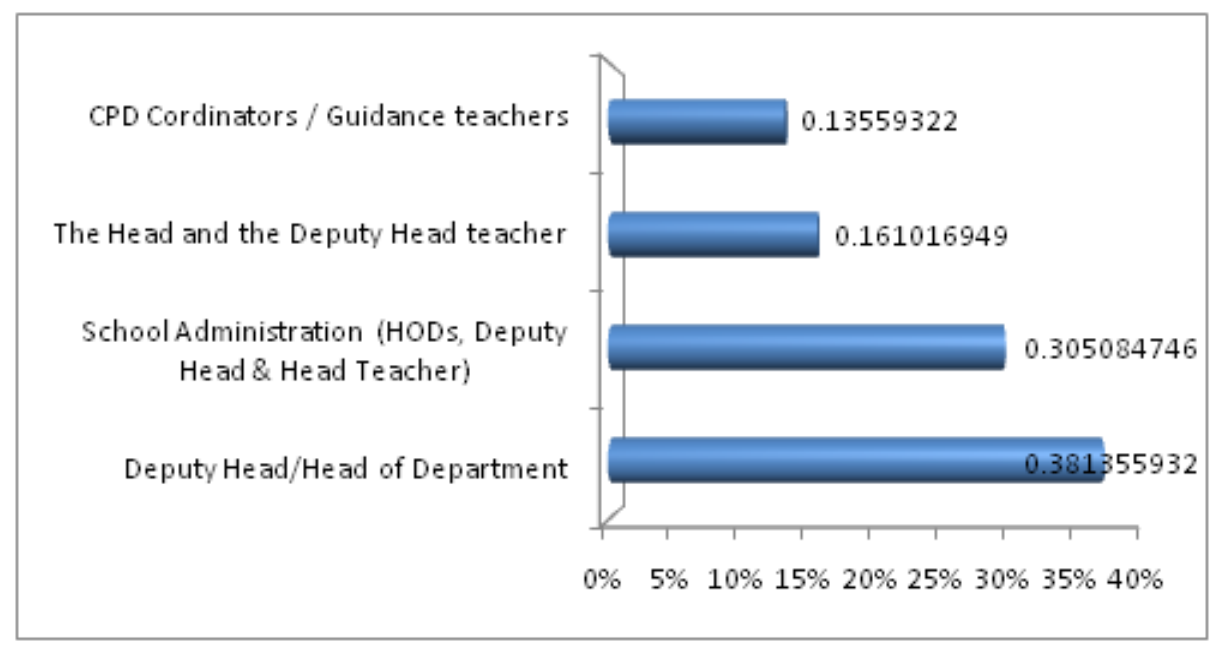

Figure10: Evaluation by Coordinators

Just like responses from the administrators, the findings of the study revealed that most of the teachers indicated that they were involved in decision making from planning level that is preparation of schemes of work in departments to lesson plan preparation and finally teaching. Most of the teachers responded that they were also involved in decision making at some level, through departmental meetings, staff meetings and staff briefings. The teachers indicated that they ensured that evaluation of their own work took place in most of the cases, Heads of Department had to just check after they had evaluated themselves.

One teacher stated that:

We are involved mostly in academic issues to do with pupil performance. We discuss results in departments and staff meeting. So I feel we are involved.

Similar to the responses by the administrators in regard to the curriculum, the findings revealed that most of the teachers said they were not involved in decisions to do with the curriculum as it came from MoGE. They further stated that they had a say on how to best to implement the curriculum meaning that to some extent they had a say through the subject associations meetings. The teachers said they were affiliated to subject associations and it was at these meetings where they discussed the curriculum in connection with the performance of the pupils for that year.

One teacher said that:

We have subject association for each subject in the country we meet once a year and it's at these workshops we discuss the curriculum and its effects. We make decisions on the curriculum based on pupil performance. I guess in this way we contribute to the decisions based on the curriculum.

Table 1 showed that 56.9 percent said they were involved, while 43.1 percent said they were not. The answers to the questionnaires do not tally with answers to the interviews. However, figure 1showed that how everyone was involved. All teachers said that they were involved in evaluating some areas in the school, 62 percent said it was through evaluation of pupils' academic progress through tests, and exams as well as pupils personal well-being. Some stated that they evaluated teachers' performance 23 percent while others were involved in self-evaluation 5 percent and 3 percent all school activities. The responses in the above figures culminate to the fact that teachers are involved in the matters of the school in various ways. Perhaps some teachers would have wanted to have direct say, but their contributions make some of management decision.

Figure 2 showed that teachers who said that they evaluated their own work were 93 percent and those who did not were 7 percent. This showed a level of involvement. 
Figure 3 showed responses by teachers that said that pupils were involved in accounting for their performance as 78 percent said yes and those who said they were not were 22 percent. More than half the number agreed to pupil involvement.

Figure 4 showed the frequency and percentage rate the teachers responded about whether the policy in their school made everyone account for their work. Figure showed frequency of 87 which translated to 77.7 percent that agreed that the policy involved everyone and the frequency of 25 translated to 22.3 percent that did not agree that the policy in their schools made everyone account for their work. More than half of the responds agreed to involvement of other people.

Figure 5 showed the teachers' responses on how pupils accounted for their performances. Analysing and accounting for individual performance 9 percent, participating in open day activities 10 percent, receiving awards/punishments depending on performance 13 percent, participating inn classroom activities such as class exercises on revisions 20 percent and through constant assessment such as tests and quizzes 47 percent. This showed that even pupils were involved in accounting for their involvement.

Figure 6 accounts for responses by the teachers as to if everyone was involved in school based selfevaluation. 66.4 percent said yes and 33.6 said no. This showed most of them agreed.

On how everyone was involved in figure 7most of the teachers' responses focused on monitoring of pupils understanding of lessons delivered, pupils' performance in tests and exams as well as monitoring of the lesson preparations, presentation and delivery by the school administration. 12 percent said teachers were involved through CPDs. 32 percent pupil assessment and 56 percent through lesson plan. Fragmented as the response may seem no one said they were not involved in monitoring. This means everyone was involved in various activities. The internal function was the responsibility of the schools themselves; schools were supposed to determine, guarantee, and guard their quality and improve the teaching/learning process and their school performance (Hofman et al., 2004a).

Of the sampled teachers (figure 8), 59.2 percent of them were involved in decision making while 40.8 percent of the respondents had no decision making powers in their respective schools. This shows this that more than half agreed to being involved in decision making.

Of the sampled teachers (figure 9), only 22 percent were involved in the formulation of school curriculum while the majority, 78 percent, was not involved in the formulation of the school curriculum. This component forms core of learning and most teachers felt they were not involved.

When asked who coordinated the school evaluations(figure 10), 14\% said it was the CPD coordinators and 16 percent indicated that it was the Deputy Head and HODs, 38 percent of the teachers said it was the deputy head or the head of their departments while 31 percent claimed it was the school administration (HODs, Deputy Head \& the Head teacher).

The findings above showed that in most schools, most stakeholders were in involved in most areas of decision making in the school, apart from the curriculum, over which school authorities had little control over as well. Ryan, Gandha, and Ahn, (2013) postulated that it would be critical to incorporate the views of a variety of key education stakeholders, including teachers as well as administrators. In this study in most activities mentioned involvement of pupils, and teachers was evident. The involvement in curriculum formulation was basically involvement in the implementation of the curriculum as it was already designed by the MoGE. However, the inspection team's recommendations and feedback were intended to help school personnel be sure they had appropriately diagnosed areas for improvement and take necessary actions (De Grauwe, 2008).

\subsection{Interviews with Pupils}

The findings were that though the pupils said that were involved in the process of planning, decision making and activities, their involvement was limited to mostly non-academic activates such as clubs and sports.

Being on represented school board by Head boy and Head girl helped them become aware of what's happening, but the involvement represented a fraction of decisions made. From the perspective of meaningful student learning, Rudd and Davies (2000) postulated that 'parents, pupils and governors 
could provide useful feedback, inform classroom practice and help to set the agenda for change'. This view is supported by that of Black and William (1998) who concluded that self-assessment was an essential component of formative assessment if it was to be used to improve student learning.

The implication of not involving the pupils in academic matters, makes it difficult for the pupils to account for their performance, resulting little academic improvement.

\subsection{Interviews with Support Staff}

On who else the support staff felt was involved in the planning and decision-making, mostly named head teacher, Deputy and Heads of Department and teachers in the procurement and accounts committee.

The findings indicate that contrary to the named stake holders in the standards and guidance document, not all stakeholders are involved in the planning and decision making. MOESVTEE (2015) named support staff as care taker, typist, and accounts assistant. Laboratory assistant, drivers, sanitary orderlies, office orderly and librarian. Though the document does not mention the stores officer, this was one of the crucial areas in the school. The other ranks of support staff such as lab assistant, librarian, care-taker were non-existent in most schools.

Findings of the objective above clearly revealed that there was a deliberate effort by the administrators to involve all stakeholders in the school activities. The only stakeholders that were not adequately involved were the support staff, some of whose departments were key to provision of quality management. For those that were involved were only involved to some areas not adequate enough to give the desired outcome.

\section{CONCLUSION AND RECOMMENDATIONS}

On identifying who was involved, the study noted that while most stakeholders understood their roles, the support staff did not understand their role in school management well. This meant that not all stakeholders were involved. The gap in the implementation of SBSE was that one section of stakeholders were left out, which had an effect on assured quality management outcome. The study concluded that without the inclusion of the all stakeholders, SBSE implementation was not complete and therefore, achieving quality management was not assured.

The findings of this study have implications for policy and practice. Therefore the study makes the following recommendations

- Ministry of General Education must ensure that there is mandatory training for all administrators before or immediately after taking office so that the administrators can acquaint themselves to all the policy documents that help them to run the schools.

- The study further recommends that deliberate policy for periodical mandatory refresher courses for the administrators to help them remain in touch with the guidelines by the MoGE.

- Furthermore, the study recommends mandatory periodical orientation of teachers over the existing policy documents in order to ascertain conformity.

- The study further recommends that communication and collaboration in the schools must be strengthened so that all stakeholders become aware of SBSE and also what part they are expected to play in order to contribute effectively to assured quality management.

\section{REFERENCES}

[1] Bonstingl, J. J. (2008), Schools of Quality, Corwin Publishers, Ilinois.

[2] Chetcuti, E. (2005), Schools' self-evaluation for improvement,

[3] Davies, (2007).Doing a Successful Project. New York: Palgrave-Macmillan.

[4] De Grauwe, A. \& Naidoo, J. P. (2004), School Evaluation for quality improvement, UNESCO, Paris, available at: http://www.education.ie/en/The-Department/Management-Organisation/Inspectorate.html (accessed on 07 July, 2016).

[5] Department of Education and Science (2003), Looking at Our School: An aid to self-evaluation in primary schools. Available at: http://www.education.ie (accessed on 30 June 2016).

[6] Department of Education and Science (2012), Guidance Teachers' standards, available at: https://www. gov.uk/government/publications/teachers-standards (accessed on 30 June 2016) 
[7] Deming, W. E. (2000), Out of the crisis (rev. ed.). MIT Press, Cambridge, MA.

[8] Hofman, R. H., Dijikstra, N. J. and Adrian, W. H.(2007).School (Self) Evaluation and Student Achievement.APERA Conference 2006.Groningen/Rotterdam: GION/RUG, RISBO/EUR.

[9] Kelchner, L. (2008), Theories of Total Quality Management, available at: http://smallbusiness.chro.com/ theories-total-quality (accessed on 19 November 2016).

[10] Lunenburg, F. C. (2010). Total Quality Management Applied to Schools, Schooling. Sam Houston State University, vol 1, No. 1.

[11] MacBeath, J. (2003), The Self-Evaluation File, Learning Files Scotland, Glasgow.

[12] MacBeath, J. (2005), Self-evaluation: Models, tools and examples of practice. available at: http://www. ncsl.org.uk/media/93C/D5/self-evaluation-models-tools-and-examples-of-practicepdf (accessed on 31 July 2016).

[13] Ministry of Education (1996), Educating our future - Policy paper of Zambian education, Ministry of Education, Lusaka.

[14] Ministry of Education Science, Vocational Training and Early Education (2015), Standards and Evaluation Guidelines, Directorate of Standards and Curriculum Department, Lusaka.

[15] Murray, A.(2014), Teacher Education Sourcebook 2014-15Teacher Education Services Murray State University, Kentucky.

[16] National Oceanic Atmospheric Administration (2000), Quality Management Program (HACCP QMP) Program Requirements, available at: https://www.st.nmfs.noaa.gov/data/Quality-Management/qualitymanagement (accessed on 03 July 2016).

[17] Office for Standards in Education (1998).School Evaluation Matters. London: Ofsted.

[18] Ryan, K. R., Gandha, T. and Ahn, J. (2013).School Self-Evaluation and Inspection for Improving U.S. Schools? University of Illinois at Urbana-Champaign. National Education Policy Center: Colorado.

[19] Scheerens, J. (2002), School self-evaluation: Origins, Definition, Approaches, Methods and Implementation, in D. Nevo (Ed.), School-based evaluation: An international

[20] School-based evaluation in the Irish context, Educational Management Administration and Leadership, 34 (14), 564-582.

\section{AUTHOR'S BIOGRAPHY}

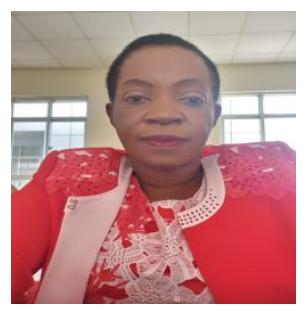

Sunshine is $\mathrm{PhD}$ holder with university of Zambia. Currently working as a head teacher at Munali girl secondary school in Lusaka Zambia.

Citation: Sunshine Namasiku Siafwa, Peter C. Manchishi, et.al. "Involvement of Stakeholders in School Based Self-Evaluation in Assuring Quality Management". International Journal of Humanities Social Sciences and Education (IJHSSE), vol.6, no.10, 2019, pp. 1-11. doi: http://dx.doi.org/10.20431/2349-0381.0610001.

Copyright: () 2019 Authors. This is an open-access article distributed under the terms of the Creative Commons Attribution License, which permits unrestricted use, distribution, and reproduction in any medium, provided the original author and source are credited. 